\title{
Problems in Standardizing Methods for Evaluating the Chilling Requirements for the Breaking of Dormancy in Buds of Woody Plants
}

\author{
F.G. Dennis, Jr. ${ }^{1}$ \\ Department of Horticulture, Michigan State University, E. Lansing, MI 48824-1325
}

Bud dormancy can be a problem in many species, both herbaceous and woody. The types of dormancy range from paradormancy (controlled by conditions within the plant but outside the bud, e.g., apical dominance), to endodormancy (controlled by conditions within the bud, e.g., failure of buds to grow in autumn) to ecodormancy (controlled by conditions outside the plant, e.g., failure of buds to grow in late winter) (Lang, 1987; Lang, et al., 1985, 1987). Dole (2001) has discussed methods of evaluating the effects of chilling in breaking dormancy in the buds of herbaceous plants. My emphasis will be on methods of evaluating the effects of temperature, especially ambient temperature, on the breaking of bud dormancy in woody plants, with emphasis on fruit trees. Saure (1985) discussed this subject in some detail in his review of dormancy.

\section{WHY BE CONCERNED ABOUT STANDARDIZATION?}

Although lack of chilling is not a problem in the higher latitudes of the temperate zone, it limits growth of many temperate-zone plants in the subtropics and tropics. In the latter regions, an evaluation of the intensity of endodormancy, or "rest," is essential for determining when rest-breaking treatments are necessary. In areas where chilling is adequate, many researchers study the phenomenon of rest for both practical and theoretical reasons. As will be seen in the discussion that follows, experimental results vary widely, even within a species. A discussion of methods may permit consensus as to the protocols to be used in such studies, leading to more consistent results.

\section{TERMINOLOGY}

Stage and depth of dormancy. The status of buds of woody plants changes with time, as they progress from paradormancy to endodormancy to ecodormancy. For convenience, I shall use the term "rest" in place of endodormancy. Rest intensifies (becomes "deeper") during the autumn, then gradually disappears as chilling removes the physiological blocks that prevent growth. However, during early phases of rest, chilling temperatures can actually increase its intensity in buds of some species (Arias and Crabbé, 1975; Walser et al. 1981).

Received for publication 4 Apr. 2002. Accepted for publication 4 Sept. 2002.

'E-mail address:fgdennis@msu.edu
Temperature requirements. Precise determination of the temperature requirements for breaking dormancy is nearly impossible under field conditions, where solar radiation, diurnal fluctuations in temperature, and other factors cannot be controlled. Diurnal changes in winter temperatures may be less pronounced in the subtropics than in the temperate zone, but they still occur. While precise determination has been attempted under laboratory conditions, the practical significance with regard to fruit trees under orchard conditions must be considered with caution because the environmental variables were constant, rather than fluctuating, i.e., "unnatural." In contrast, producers of pot plants for the Easter market will find precise temperature requirements of considerable value (see Dole, 2001), as the temperature can be controlled relatively easily.

End of rest. Investigators often speak of the "end of rest" when evaluating bud dormancy. This is usually defined as the time when $50 \%$ of the buds on excised shoots are capable of growth within a given period of time when held at an appropriate temperature with their bases in water. As pointed out by Couvillon and Erez (1985), this is not truly the end of rest, but an arbitrary point in the breaking of rest; more chilling will permit $>50 \%$ of the buds to grow. Nevertheless, it is "useful for measurement ... and comparison ..." (Seeley, 1996). An additional problem, discussed in more detail below, is determining what constitutes "growth." Greening of the bud scales is sometimes taken as evidence of "budbreak," but whether this really represents "end of rest" in a given bud is questionable.

\section{MODELS FOR DETERMINING CHILLING REQUIREMENT}

In order to determine what temperatures are effective under field conditions, many models to predict the response of buds of woody plants to chilling have been proposed, including some for forest trees, e.g., Picea sitchensis (Bong.) Carr. (Cannell and Smith, 1983), and red osier dogwood (Cornus sericea L.) (Kobayashi etal., 1982). Lang (1989) briefly reviewed several of the models tested with tree fruits. Seeley (1996) provided a more complete review of the modeling studies that formed the basis for the "Utah" model and modifications thereof. Cannell's (1989) discussion of environmental "clues" for blossoming and budbreak includes a review of four bases for such models. These posit that: 1) budbreak occurs after a fixed thermal time (i.e., accumulation of heat units) in spring;2) a fixed chilling time must occur prior to accumulation of thermal time; 3) (1) and (2) are interrelated; and 4) autumn conditions, chilling, thermal time and photoperiod can be combined in modeling. Cannell (1989, p. 110) cautions that "there is a great deal to learn about the environmental cues for blossoming and budburst before mechanistic models can be written with any predictive value." Seeley (personal communication) also notes that the responses of buds to both temperature and photoperiod can vary greatly among species and cultivars; therefore, the temperature requirements must be established for each cultivar before models can be used.

Among the models proposed for fruit trees was the relatively simple one of Weinberger (1950), based on his work with peach [Prunus persica (L.) Batsch.] in Georgia. He defined 1 chilling hour $(\mathrm{CH})$ as $1 \mathrm{~h}$ at or below 45 ${ }^{\circ} \mathrm{F}\left(7.2{ }^{\circ} \mathrm{C}\right)$. Temperatures below $0{ }^{\circ} \mathrm{C}$ were considered to have no effect in breaking dormancy (such temperatures were apparently rare at lower elevations in central Georgia). Weinberger (1967) later suggested that the chilling effect was partially reversible, based upon the delay in budbreak induced by high temperatures in November and December. In 1974, Richardson et al. published a description of their "Utah Model," in which temperatures between 0 and $16^{\circ} \mathrm{C}$ promote the breaking of rest, whereas temperatures $>16^{\circ} \mathrm{C}$ negate such effects. Maximum promotion occurs at $7{ }^{\circ} \mathrm{C}$ $\left[1 \mathrm{~h}\right.$ at $7^{\circ} \mathrm{C}=1$ "chill unit" $\left.(\mathrm{CU})\right]$; higher and lower temperatures within the $0-16^{\circ} \mathrm{C}$ range are less effective. This model has been modified as more information has become available (see Seeley, 1996).

The Utah model has been used successfully, with or without minor modifications, in the cool temperate zone. However, in the warm temperate zone and/or subtropics, it is less useful. Temperature and phenological data for northern Mexico were used as a basis for revising the model; this increased the coefficient of determination from $66 \%$ to $74 \%$ (del Real-Laborde, 1989). Erez et al. (1988, 1990) proposed the "dynamic model", in which temperatures between 0 and $13{ }^{\circ} \mathrm{C}$ have positive effects and those above $18{ }^{\circ} \mathrm{C}$ have negative ones. However, response varies with time of exposure, and temperatures of 13 to $16^{\circ} \mathrm{C}$ may enhance response if cycled with lower temperatures. This model is based on experiments with peach under controlled conditions, and on theoretical concepts developed by Fishman, et al. (1987a, 1987b), with one "chill portion" being defined as exposure to $6^{\circ} \mathrm{C}$ for $28 \mathrm{~h}$. The dynamic model differs from the Utah Model in that chilling units, once accumulated, cannot 
be negated by high temperature. Allan et al. (1993), working in South Africa, compared the two models, including a modification of the Utah Model with no allowance for negation by warm temperatures. They found the dynamic model to be a better indicator of the response of peach trees to chilling in the subtropics (Table 1); eliminating negative values from the Utah Model greatly improved its predictive value.

\section{PROTOCOLS FOR EVALUATING DEPTH OF DORMANCY}

Choice of experimental unit. Samish and Lavee (1962) noted the lack of standardization in methods used to evaluate the depth of dormancy. Little has changed in the last 40 years; some of the reasons for this are indicated below. To properly evaluate the depth of dormancy in the entire plant, it should be exposed to temperatures suitable for growth, as in a greenhouse, but this is difficult with large plants. In a series of experiments, Erez et al. (1979) used rooted cuttings of peach to study the effects of alternating temperatures in breaking bud dormancy. One might ask whether the presence of roots in close proximity to the buds might affect response; however, Couvillon et al. (1975) had previously demonstrated that budbreak on rooted cuttings paralleled that on mature trees. Saltveit (1983), although not studying dormancy, described a method for growing small apple [Malus domestica (L.) Mill. var. domestica (Borkh.) Mans.] trees in pots, chilling them, and returning them to the growing area. He tested various cycle times and observed that longer growth periods resulted in better fruit set following chilling. Several workers, e.g., Mauget (1983), have used similar, but larger, potted trees; however, this makes replication more difficult.

Most investigations of bud dormancy have been carried out by forcing cuttings from trees that were exposed to natural conditions. Arias and Crabbé (1975) observed that the responses of excised shoots of sweet cherry (Prunus avium L.) paralleled those of whole plants. However, Williams et al. (1979) observed that, although excised apple shoots forced at $25^{\circ} \mathrm{C}$ failed to grow when sampled in autumn, similar shoots grew readily when decapitated, exhibiting, in effect, no rest. They ascribed the promotive effect of decapitation to ethylene produced following wounding. Other workers have reported similar, but less dramatic, effects of decapitation of apple cuttings (Paiva and Robitaille,1978; Swartz et al., 1984; Williams et al.,1979). Paiva and Robitaille (1978) also noted that the terminal bud had a lower chilling requirement than did the lateral buds, and that wound ethylene did not appear to play a role in stimulating budbreak. The stem itself can inhibit bud development in some species; when distal buds were removed from Rhamnus frangula L. cuttings, development of the single remaining lateral bud was delayed relative to that of a similar bud on a cutting from which the entire distal portion had been removed (Meng-Horn, et al., 1975). Ethylene production was not measured in this study.

Table 1. Comparison of models for estimating chill unit accumulation in a subtropical environment at Pietermaritzburg, S. Africa. [Adapted from Allan et al. (1993)]

\begin{tabular}{lcccc}
\hline & \multicolumn{4}{c}{ Model } \\
\cline { 2 - 5 } Year & $\begin{array}{c}\text { Weinberger }^{\mathrm{z}} \\
(\mathrm{CU})\end{array}$ & $\begin{array}{c}\text { Utah }^{\mathrm{y}} \\
+ \text { and }-\end{array}$ & $\begin{array}{c}(\mathrm{CU}) \\
+ \text { only }\end{array}$ & $\begin{array}{c}\text { Dynamic }^{\mathrm{x}} \\
(\mathrm{CP})\end{array}$ \\
\hline 1990 & 67 & -6 & 223 & 13.2 \\
1991 & 43 & 139 & 226 & 16.1 \\
$1992^{\mathrm{w}}$ & 208 & -18 & 147 & 10.8 \\
\hline
\end{tabular}

${ }^{\mathrm{z}}$ Total no. of hours $<7.2^{\circ} \mathrm{C} .1$ hour $=1$ chill unit $(\mathrm{CU})$

${ }^{y}$ Temperatures between 0 and $16^{\circ} \mathrm{C}$ have varying effects, with a maximum at $7.2^{\circ} \mathrm{C} .1 \mathrm{CU}=1 \mathrm{~h}$ at $7.2^{\circ} \mathrm{C}$. Temperatures $>16^{\circ} \mathrm{C}$ negate accumulation of CUs, regardless of timing. $+/-=$ Sum of positive and negative values; +- negative values ignored.

${ }^{\mathrm{x}} 1$ chilling portion $(\mathrm{CP})=28 \mathrm{~h}$ at $7{ }^{\circ} \mathrm{C}$. Temperatures $>13{ }^{\circ} \mathrm{C}$ do not negate accumulation of CPs, once acquired.

"Mildest winter, budbreak delayed in high-chill cultivars

To avoid the influence of one plant part on another (apical dominance, competition between buds, effect of apical portion of stem), Crabbé (1968, 1994, and references therein) used single-node cuttings of woody plants, including fruit trees, in his studies. He and his students demonstrated that buds from the distal and proximal portions of sweet cherry cuttings differed considerably in their ability to grow. The basitonic gradient (greater response of buds in the basal than in the apical portion of the cutting) evident early in the dormant period shifted to an acrotonic one (greater response of buds in the terminal portion) near the end of rest (Crabbé, 1968). Budbreak in cherry was greatly delayed in late summer/early autumn, but was hastened by exposure to chilling thereafter. In apple cuttings, a similar delay in bud break was observed in late autumn, but not before or after (Ben Ismail, 1989). Williams et al. (1979) also compared the growth of buds on single-node cuttings of apple with that of buds on decapitated cuttings; all buds grew equally well, regardless of the hours of chilling received. Again, they concluded that cutting the shoots overcame rest by inducing ethylene production. To my knowledge, no one has verified this by evaluating the effects of inhibitors of ethylene synthesis (e.g., 2,5norbornadiene) or action (e.g., $\mathrm{AgNO}_{3}$ ) on response. Meng-Horn et al. (1975) reported that development of apical buds on cuttings of Rhamnus frangula sampled in late winter was more rapid when the subtending disbudded stem exceeded $4 \mathrm{~cm}$ in length; however, no effect of stem length was observed when lateral buds were used. However, the former experiment was performed in February, the latter in March, hence the effect of bud type (terminal vs. lateral) was not compared directly. Plancher (1983) observed that the chilling requirements of buds on single-node cuttings were lower than those of buds on intact plants of black currant (Ribes nigrum L.), and that basal buds opened first when isolated, rather than last. He concluded that single-node cuttings were unsuitable for quantitative investigations.

The bases of cuttings, be they long or short, must be recut frequently to prevent vessel occlusion. Another problem is the danger of desiccation unless they are kept under high humidity, as in a mist bed. Growing cuttings and/or buds in vitro can prevent this. Schneider $(1968,1970)$ cultured buds of rhododendron in vitro to determine the effects of various factors, including bud scales, on dormancy. He found that response paralleled that of buds in situ on the plant. Swartz et al. (1984) used a similar technique with single-node cuttings of apple. Removal of the scales promoted growth without affecting ethylene production, but only during rest.

Choice of experimental unit ultimately depends upon the goals of the research. If one's main concern is practical application, the larger the unit, the better, as this best represents the whole tree, with all the dynamic relationships and complications of apical dominance and other correlative effects. If, on the other hand, the goal is to study the physiological basis of rest, in its most restrictive sense, the smaller the unit, the better, with single buds (or even meristems) being the units of choice - provided that methods are employed to prevent artifacts, such as stimulation of ethylene production.

Criteria for determining depth of rest. Two main criteria have been used to determine the depth of rest in cuttings (cf. Saure, 1985), viz.: 1) percentage budbreak within a given period of time, and 2) time required to reach a given stage of development. A common procedure is to record the percentage of buds that break within 3 or 4 weeks, but, as noted above, "budbreak" may be defined in a number of ways. Hatch and Walker (1969), noting that peach and apricot (Prunus armeniaca L.) buds did not grow at all until mid-December in Utah, used the concentration of gibberellin required to stimulate bud enlargement (scale greening) as a measure of the depth of dormancy; the higher the concentration required, the more dormant the buds. However, this is a questionable criterion for the breaking of dormancy. Plancher (1985) considered the rapid unfolding of leaves and growth of shoots to be an indication of the end of rest. Ideally, the percentage of buds that reach full bloom (flower buds), or that open fully (vegetative buds) would be useful criteria, but cuttings often exhaust their reserves, and/or the conductive vessels become plugged, before these stages are reached. Although the bases of the cuttings can be recut frequently to avoid such plugging, the system is not ideal. Best results are obtained with cuttings up to 
a meter or more in length; I have even been able to set small fruit on fully chilled apple branches of this size (unpublished data). Erez (1999 and personal communication) indicates that there are two phases in the growth of buds. In vegetative buds, the first phase is emergence of the leaves, the second is elongation of the axis; in flower buds, the first phase is anthesis, the second fruit set. When chilling is insufficient, buds open and form rosettes, but do not develop further, and flowers fail to set fruit, especially in stone fruit. Because both phases cannot be achieved with cuttings, Erez prefers to use whole trees.

Of the two methods of measuring response (the time required to reach a specific stage of bud opening vs. percentage budbreak within a fixed time interval), the former appears to be the better, especially if the criteria for budbreak are well-defined. Saure (1985) also considered this criterion ("speed of budbreak") to be the better of the two.

Environmental conditions. In evaluating chilling requirements, the temperature(s) of exposure during both the dormant period and the test period must be considered. Saure (1985), Seeley (1996), and others have suggested that the optimum temperatures for chilling - and for negating the effects of chilling - may vary with the stage of rest. However, in this paper, I will discuss only the temperature during the forcing period. The optimum temperature for budbreak varies with stage of dormancy, as it does in some seeds (reviewed by Vegis, 1964). Apple buds on single-node cuttings grew much more slowly at $15^{\circ} \mathrm{C}$ than at $25^{\circ} \mathrm{C}$ when chilling was minimal; as chilling continued, they grew nearly as well at the lower as at the higher temperature (Crabbé, 1994). Whether this needs to be considered in forcing cuttings is debatable, given that buds on intact trees do not break in the fall despite exposure to temperatures of $15^{\circ} \mathrm{C}$ or higher. However, in studies of rest, per se, the higher temperature may negate previous chilling. Seeley (personal communication) considers the optimum forcing temperature to be near $15^{\circ} \mathrm{C}$, which neither promotes nor negates the breaking of dormancy. Although alternating temperatures are more effective than constant ones in stimulating germination of some seeds (see Geneve, 2003), and in breaking rest in peach buds (Erez et al., 1979), I am aware of no data to indicate that alternating temperatures favor bud break during forcing.

Exposure to light can affect budbreak in some species. Coville (1920) reported that budbreak and shoot growth occurred on intact blueberry (Vaccinium corymbosum L.) plants stored in the dark at $36^{\circ} \mathrm{F}\left(2{ }^{\circ} \mathrm{C}\right)$; however, he did not compare bud development in darkness vs. light. Erez et al. $(1966,1968)$ found that vegetative buds, but not flower buds, of peach required exposure to light for best response. Terminal buds were less affected than lateral buds. Similarly, opening of buds of beech (Fagus sylvatica L.) is promoted by light (Wareing, 1953). Given that trees receive solar radiation under orchard conditions, light should be supplied for cuttings in determining chilling requirements, unless it can be shown to have no effect. Relative humidity is critical for bud development lest the cuttings become desiccated. Therefore, a high RH should be maintained, either by using a vapor barrier, such as a plastic covering, or by placing cuttings in a mist bed.

\section{SUMMARY}

Modeling can be useful in predicting budbreak, especially in the subtropics, where special treatments may be required to supplement natural chilling. It has limited practical use in the cooler temperate regions, as chilling is always adequate. The Utah Model appears to be reliable in the cooler regions, whereas the dynamic model may be more useful in warmer zones. Regardless of the model used, attention must be paid to species and cultivar, and appropriate adjustments made.

To standardize methods for determining the stage of rest, researchers should first decide upon the portion of the plant to be used as the experimental unit (e.g., single-node cutting, entire cutting, rooted cutting, whole plant). This will vary, of course, with the purpose of the research. Single-node cuttings are of little use for determining response of whole trees, as bud development in the latter will be affected by correlative inhibition, including apical dominance. Cuttings bearing many buds will be the better choice for researchers wishing to predict the field response. The larger the cutting, the better the expected response. The source of cuttings is also important, especially for theoretical studies; previous year's shoots are normally used, but their vigor could affect response. Therefore, selected shoots should be similar in length and taken from similar positions on the plant. The environmental conditions to be used, especially temperature, must be established for each species and cultivar used. A temperature of $15-20{ }^{\circ} \mathrm{C}$ should be adequate. Light should be supplied unless it can be shown to have no effect.

The criteria to be used for evaluation of response, including observation time and stage of bud development, must also be agreed upon. These conditions will undoubtedly differ among species, but some agreement should be possible within species. Greening of the bud scales alone appears to be too limited a response to predict behavior under orchard conditions. On the other hand, full bloom may be difficult to obtain with small cuttings. Recording time to reach a given stage of development ("speed of budbreak") appears to be superior to recording the percentage budbreak during a specific time interval. The problem with the method is selecting a stage that will be reached by partially chilled buds so that comparisons can be made throughout the period of dormancy. Otherwise, response can be quantified only during the later stages of dormancy.

Despite all precautions, differences in results will occur; e.g., contrast the results of several workers in using single-node cuttings of apple (see above). Such differences may reflect differences in choice of plant material, or in environmental conditions during the previous growing season. Some of these problems might be solved by using a cooperative approach. For example, experimental protocols could be established and tested by researchers at several locations, using the same cultivars, and/or cuttings could be exchanged, so that the responses of cuttings from the same trees could be compared at different locations.

\section{Literature Cited}

Allan, P., G. Rufus, G. Linsley-Stokes, and G. Matthee. 1993. Winter chill models in a mild subtropical area and effects of constant $6{ }^{\circ} \mathrm{C}$ chilling on peach budbreak. Acta Hort. 409:9-17.

Arias, O. and J. Crabbé. 1975. Les gradients morphogénétiques du rameau d'un an des végétaux ligneux en repos apparent. Données complementaires fournies par l'etude de Prunus avium L. Physiol. Vég. 13:69-81.

Ben Ismail, M.C. 1989. Dormancy et reprise de la croissance des bourgeons chez les arbres fruitiers. PhD Diss., Faculté des Sciences Agronomique de Gembloux, Belgium.

Cannell, M.G.R. 1989. Chilling, thermal time and the date of flowering of trees, p. 99-113. In: C.J. Wright (ed.). Manipulation of fruiting. Butterworths, London.

Cannell, M.G.R. and R.I. Smith. 1983. Thermal time, chill days and prediction of budburst in Picea sitchensis. J. Appl. Ecol. 20:951-963.

Couvillon, G.A. and A. Erez. 1985. Influence of prolonged exposure to chilling temperatures on bud break and heat requirement for bloom of several fruit species. J. Amer. Soc. Hort. Sci. 110:47-50.

Couvillon, G.A., G.A. King, C.M. Moore, and P. Bush. 1975. Obtaining small peach plants containing all bud types for "rest" and dormancy studies. HortScience 10:78-79.

Coville, F.V. 1920. The influence of cold in stimulating the growth of plants. J. Agr. Res. 20: 151-160.

Crabbé, J. 1968. Evolution annuelle de la capacité intrinsèque de débourrement des bourgeons successifs de la pouse de l'année chez le pommier et le poirier. Bul. Soc. Royale Bot. Belgique 101:195-204.

Crabbé, J. 1994. Dormancy. Encyclop. Agr. Sci. 1: 597-611. Academic, New York.

del Real-Laborde, J.I. 1989. An apple test model for mild winter conditions. PhD Diss., Plant Sci. Dept., Utah State Univ., Logan.

Dole, J. 2003. Standardizing methods for evaluating the chilling requirements for the breaking of dormancy in bulbs, corms, and tubers. HortScience 38:341-346.

Erez, A. 1999. Dormancy completion-A dual response. HortScience 34:524-525. (Abst.)

Erez, A., G.A. Couvillon, and C.H. Hendershott. 1979. Quantitative chilling enhancement and negation in peach buds by high temperatures in a daily cycle. J. Amer. Soc. Hort. Sci. 104: 573-576.

Erez, A., S. Fishman, Z. Gat, and G.A. Couvillon. 1988. Evaluation of winter climate for breaking bud rest using the dynamic model. Acta Hort. 232:76-89.

Erez, A., S. Fishman, G.C. Linsley-Noakes, and P. Allan. 1990. The dynamic model for rest completion in peach buds. Acta Hort. 276:165-173.

Erez, A., S. Lavee, and R.M. Samish. 1968. The effect of limitation of light during the rest period on leaf bud break of the peach (Prunus persica). Physiol. Planta. 21:759-764.

Erez, A., R.M. Samish, and S. Lavee. 1966. The role of light in leaf and flower bud break of the peach (Prunus persica). Physiol. Planta. 19:650-659. 
Fishman, S.,A.Erez, and G.A. Couvillon. 1987a. The temperature dependence of dormancy breaking in plants: Two-step model involving a cooperative transition. J. Theor. Biol. 124:473-483.

Fishman, S., A. Erez, and G.A. Couvillon. 1987b. The temperature dependence of dormancy breaking in plants: Simulation of processes studied under controlled temperatures. J. Theor. Biol. 126:309-322.

Geneve, R.L. 2003. The influence of temperature on seed dormancy. HortScience 38:336-341.

Hatch, A. and D.R. Walker. 1969. Rest intensity of dormant peach and apricot leaf buds as influenced by temperature, cold hardiness, and respiration. J. Amer. Soc. Hort. Sci. 94:304-307.

Kobayashi, K.D., L.H. Fuchigami, and M.J.English. 1982. Modeling temperature requirements for rest development in Cornus sericea. J. Amer. Soc. Hort. Sci. 107:914-918.

Lang, G.A. 1987. Dormancy: A new universal terminology. HortScience 22:817-820.

Lang, G. A. 1989. Dormancy-Models and manipulations of environmental/physiological regulation, p. 79-98. In: C.J.Wright (ed.). Manipulation of fruiting. Butterworths, London.

Lang, G.A., J.D. Early, N.J. Arroyave, R.L. Darnell, G.C. Martin, and G.W. Stutte. 1985. Dormancy: Toward a reduced, universal terminology. HortScience 20:809-812.

Lang, G.A., J.D. Early, R.D. Darnell, and G.C. Martin. 1987. Endo-, para-, and ecodormancy: Physiological terminology and classification for dormancy research. HortScience 22:371-377.

Mauget, J.C. 1983. Etude de la levée de dormance et du débourrement des bourgeons de noyer
(Juglans regia L., cv. "Franquette") soumis à des températures supérieures a $15^{\circ} \mathrm{C}$ au cours de leur période de repos apparent. Agronomie 3(3):745-749. (Hort. Abstr. 54:624)

Meng-Horn, C., P. Champagnat, P. Barnola, and S. Lavarenne. 1975. L'axe caulinaire, facteur de préseances entre bourgeons sur le rameau de l'année du Rhamnus frangula L. Physiol. Vég. 3: $335-348$

Paiva, E. and H.A. Robitaille. 1978. Breaking bud rest on detached apple shoots: Effects of wounding and ethylene. J. Amer. Soc. Hort. Sci. 103: 101-104.

Plancher, B. 1983. Chilling requirement of rooted layers, detached shoots, and single-node cuttings of Ribes nigrum L. (in German). Gartenbauwissenschaft 48:248-255.

Plancher, B. 1985. Remarks regarding the reproducibility and comparability of results on quantitative chilling requirements (in German). Erwerbsobstbau 27:271-275.

Richardson, E.A., S.D. Seeley, and D.R. Walker. 1974. A model for estimating the completion of rest for 'Redhaven' and 'Elberta' peach trees. HortScience 9:331-332.

Saltveit, M. 1983. Year-round production of apple fruit from container-grown trees. HortScience 18:919-920.

Samish R.M. and S. Lavee. 1962. The chilling requirement of fruit trees. Proc. 16th Intl. Hort. Congr. 5:372-388.

Saure, M. 1985. Dormancy release in deciduous fruit trees. Hort. Rev. 7:239-299.

Schneider, E.F. 1968. The rest period of Rhododendron flower buds. 1. Effect of the bud scales on the onset and duration of rest. J. Expt. Bot. 19: 817-824.

Schneider, E.F. 1970. The rest period of Rhododendron flower buds. II. Studies on the rest period in tissue culture and in situ. J. Expt. Bot. 221: 799-807.

Seeley, S.D. 1996. Modelling climatic regulation of bud dormancy, p. 361-376. In: G.A. Lang (ed.). Plant dormancy: Physiology, biochemistry, and molecular biology. CAB Intl., Wallingford, Oxon, U.K.

Swartz, H.J., A.S. Geyer, L.E. Powell, and S.-H. C. Lin. 1984. The role of bud scales in the dormancy of apples. J. Amer. Soc. Hort. Sci. 109:745-749.

Vegis, A. 1964. Dormancy in higher plants. Annu. Rev. of Plant Physiol. 15:185-224.

Walser, R.H., D.R. Walker, and S.D. Seeley. 1981. Effect of temperature, fall defoliation, and gibberellic acid on the rest period of peach leaf buds. J. Amer. Soc. Hort. Sci. 106:91-94.

Wareing,P.F. 1953. Growth studies in woody species. V. Photoperiodism in dormant buds of Fagus sylvatica L. Physiol. Planta. 6:692-706.

Weinberger, J. 1950. Chilling requirements of peach varieties. Proc. Amer. Soc. Hort. Sci. 56:123-133.

Weinberger, J. 1967. Some temperature relations in natural breaking of the rest of peach flower buds in the San Joaquin Valley, California. Proc. Amer. Soc. Hort. Sci. 91:84-89.

Williams, R.R., G.R. Edwards, and B.G. Coombe. 1979. Determination of the pattern of winter dormancy in lateral buds of apples. Ann. Bot. 44:575-581. 